\title{
Unilateral Post-LASIK Ectasia in a Topographical Normal Eye with a Slight Asymmetry in the Contralateral Eye
}

\author{
${ }^{1}$ Marouen Berguiga, ${ }^{2}$ Alain Saad, ${ }^{3}$ Damien Gatinel
}

\begin{abstract}
Purpose: To report a case of post-LASIK unilateral corneal ectasia.
\end{abstract}

Setting: Department of Anterior Segment and Refractive Surgery, Rothschild Foundation, Paris.

Case report: A 33-year-old woman was referred with a history of unilateral post-LASIK ectasia in her left eye, 18 months post operatively. Her best-corrected visual acuity was $20 / 20$ with a manifest refraction of $+1.75(-4.75 \times 90)$. Orbscan $\|^{\circledR}$ revealed an inferior steepening associated with irregular astigmatism. The preoperative Placido topographies revealed a slight skewed radial axis in the right eye associated with an inferior-superior keratometry difference of 1.6 Diopters at $3 \mathrm{~mm}$. In the left eye that developed ectasia, regular symmetric astigmatism was present. Uncorrected visual acuity improved to 20/25 2 weeks after KeraRing ${ }^{\circledR}$ segment insertion.

Keywords: LASIK, Ectasia, Intrastromal corneal ring segments, Femtosecond.

How to cite this article: Berguiga M, Saad A, Gatinel D. Unilateral Post-LASIK Ectasia in a Topographical Normal Eye with a Slight Asymmetry in the Contralateral Eye. Int J Kerat Ect Cor Dis 2014;3(1):47-51.

Source of support: Nil

Conflict of interest: None declared

\section{INTRODUCTION}

Corneal ectasia is an uncommon but serious vision-threatening complication of refractive surgery. ${ }^{1-6}$ It is characterized by a progressive topographic steepening associated with visual acuity loss. As the number of patients who have refractive surgery increases, more cases of ectasia are being recognized. Ectasia usually occurs within the first year of surgery, although cases have been reported up to 10 years postoperatively. ${ }^{7-11}$ Most reported cases have topographic evidence of keratoconus

\footnotetext{
${ }^{1}$ Department of Anterior Segment and Refractive Surgery Rothschild Foundation, Paris, France

${ }^{2,3}$ Department of Anterior Segment and Refractive Surgery Rothschild Foundation, Center of Expertise and Research in Optics for Clinicians, Paris, France

Corresponding Author: Alain Saad, Department of Anterior Segment and Refractive Surgery, Rothschild Foundation Paris, France, Phone: +33148036482, e-mail: dralainsaad@ gmail.com
}

suspect, frank keratoconus, or pellucid marginal degeneration preoperatively. ${ }^{12,13}$ From the reported cases, a variety of risk factors have been proposed, including young age, high myopia, low residual stromal bed thickness, and low preoperative corneal thickness. $^{7}$

Intracorneal rings are PMMA segments that were initially approved by the US FDA and the european community $(\mathrm{CE})$ for management of myopia and astigmatism. ${ }^{14-17}$ Recent studies have reported their effective use for the treatment of keratoconus and ectasia resulting from keratorefractive surgery. ${ }^{18}$ Treatment with intrastromal rings does not eliminate the progression of keratoconus, but it may delay a corneal transplant procedure.

We report the clinical and topographic findings of a patient who developed unilateral corneal ectasia one and a half years after laser in situ keratomileusis (LASIK) and have benefit from an intrastromal corneal ring implantation.

\section{CASE REPORT}

A 33-year-old woman was referred to our practice for the management of a complicated LASIK surgery, which had been performed bilaterally in September 2010. The preoperative refraction was $-7(-1.5 \times 10)$ in the right eye and $-7(-2.25 \times 170)$ in the left eye. The corrected distance visual acuity (CDVA) was 20/20 in both eyes. Corneal topography obtained with an Orbscan II (Bausch and Lomb) revealed a mean keratometric power of 42.3D in the right eye and 41.9D in the left eye (Fig. 1). Anterior and posterior elevations were normal in both eyes. The Placido topographies revealed a slight skewed radial axis in the right eye (A) associated with an inferior-superior keratometry difference of $1.6 \mathrm{D}$, at $3 \mathrm{~mm}$. In the left eye (B), regular symmetric astigmatism was present.

The patient had no family history of keratoconus and no personal history of allergy or eye rubbing but reported moderate dry eye. The mean central pachymetry was $511 \mathrm{~mm}$ in the right eye (thinnest point $509 \mathrm{~mm}$ ) and $526 \mathrm{~mm}$ in the left eye (thinnest point $519 \mathrm{~mm}$ ). A femtosecond laser (IntraLase) was used to create the flap. The surgeon did not indicate any surgical complication in the operative note, and there was no documentation of intraoperative corneal thickness measurement. One month postoperatively, the uncorrected distance visual acuity (UDVA) was 20/20 in 


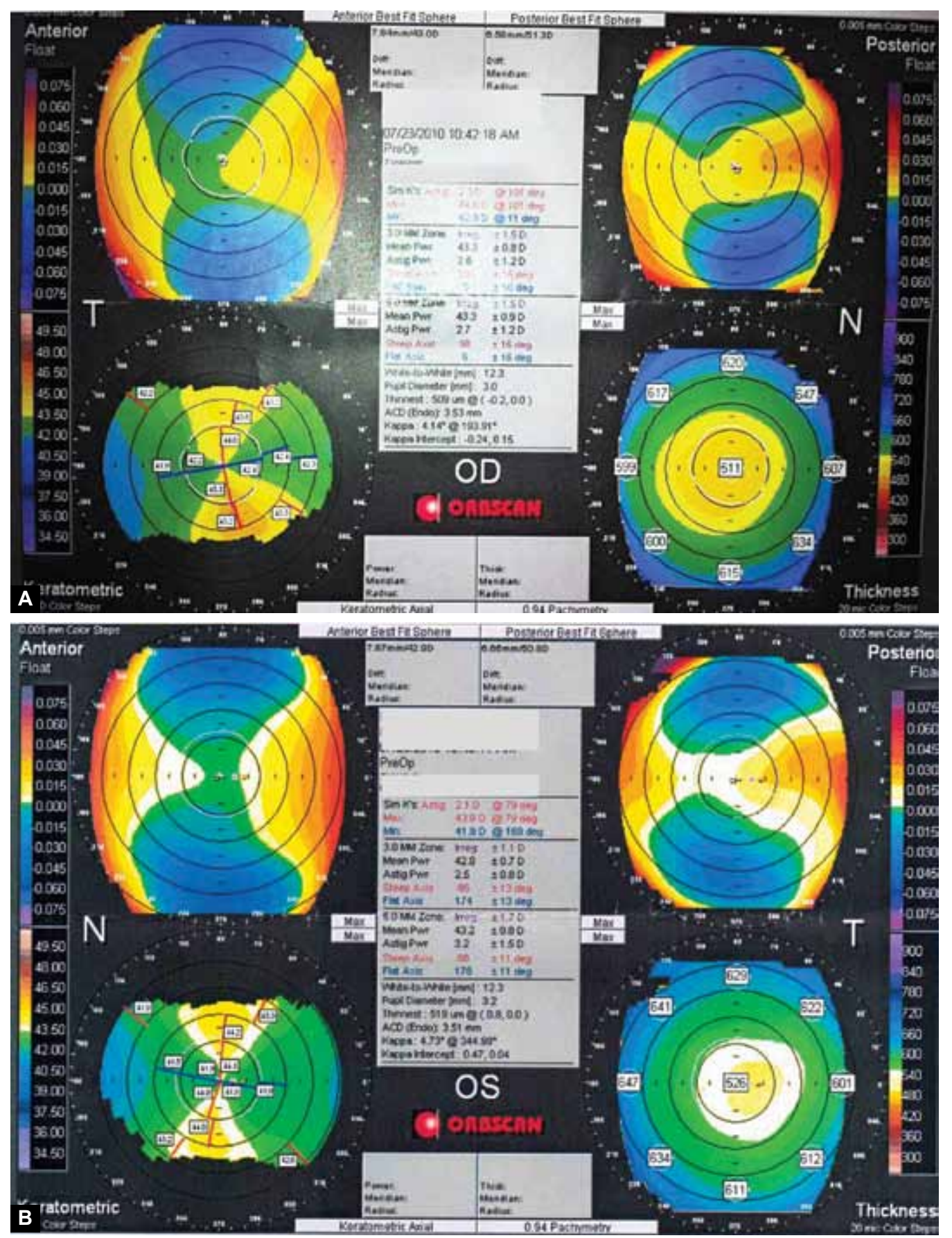

Figs 1A and B: Right (A) and left (B) preoperative corneal topographies (Orbscan Quadmaps) showing normal anterior and posterior elevations maps in both eyes. On the Placido map, there is a slight skewed radial axis in the right eye associated with an inferior-superior keratometry difference of 1.6 Diopters at $3 \mathrm{~mm}$

both eyes. The UDVA remained 20/20 in both eyes until May 2012, when the patient presented to our practice with blurring of vision.

On examination, the UDVA was $20 / 20$ in the right eye and $20 / 50$ in the left eye. The left eye visual acuity could be improved to $20 / 20$ with a correction of $+1.75(-4.75 \times$ 90). Specular and elevation topography (Figs $2 \mathrm{~A}$ and B) (Orbscan II) showed bilateral inferior steepening, more significant in the left eye. Anterior segment optical coherence tomography (OCT) showed a central flap thickness of 123 $\mu \mathrm{m}$ with a residual stromal bed thickness of $349 \mu \mathrm{m}$ in the right eye and $111 \mu \mathrm{m}$ and $335 \mu \mathrm{m}$ respectively, in the left eye (Figs $3 \mathrm{~A}$ and $\mathrm{B}$ ).

The patient was reluctant to the use of contact lenses and in an attempt to improve the vision, ICRS (KeraRing ${ }^{\circledR}$, Medi-phacos Inc, Belo Horizonte, Brazil) implantation was planned. One segment Keraring SI6 with 250 $\mu \mathrm{m}$ thickness and 150 arcs was placed inferotemporally. The femtosecond laser (IntraLase ${ }^{\circledR}$, Advanced Medical Optics, Inc, Abbott Park, IL) was used to create intrastromal channels for ICRS at a depth of $360 \mu \mathrm{m}$ with inner and outer diameters of 6.0 and $7.2 \mathrm{~mm}$, respectively. A disposable 

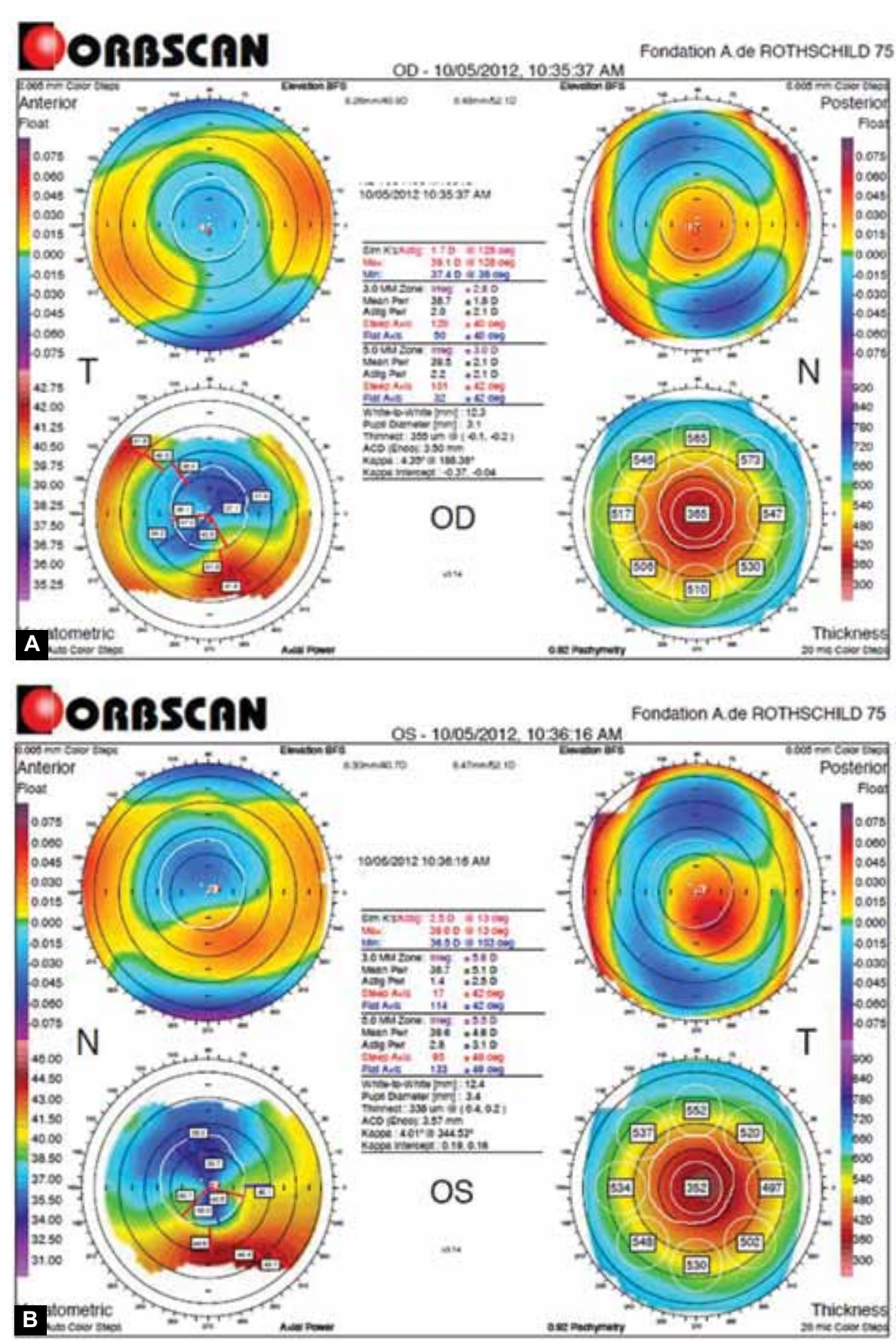

Figs 2A and B: Right (A) and left (B) postoperative corneal topographies (Orbscan Quadmaps) showing an inferior steepening in the left eye

suction ring and an applanation cone were used to stabilize and flatten the cornea to maintain a precise distance from the laser head to the focal point.

\section{Postoperative Course}

In her examination 2 weeks postsurgery, the patient's UCVA was $20 / 25$ and improved to $20 / 20$ at 1 year postoperatively. Slit-lamp examination revealed well-centered intracorneal ring with no migration or inflammatory reaction (Fig. 4). On Orbscan $\mathrm{II}^{\circledR}$ topography, minimum and maximum simulated $\mathrm{K}$ readings were 36.7D and 37.1D, respectively (Fig. 5). Visante $^{\circledR}$ (Carl Zeiss Meditec Inc, Dublin, CA) anterior segment optical coherence tomography displayed that the intrastromal channels were created at a depth of 350 microns.

\section{DISCUSSION}

Corneal ectasia following LASIK is an enigmatic complication, and the reason it develops in some patients with few evident risk factors remains unknown. Many authors think biomechanical properties may play a role in detecting at-risk corneas, and therefore have described some biomechanical criteria and thresholds that may help in distinguishing atrisk corneas. ${ }^{19-21}$ 


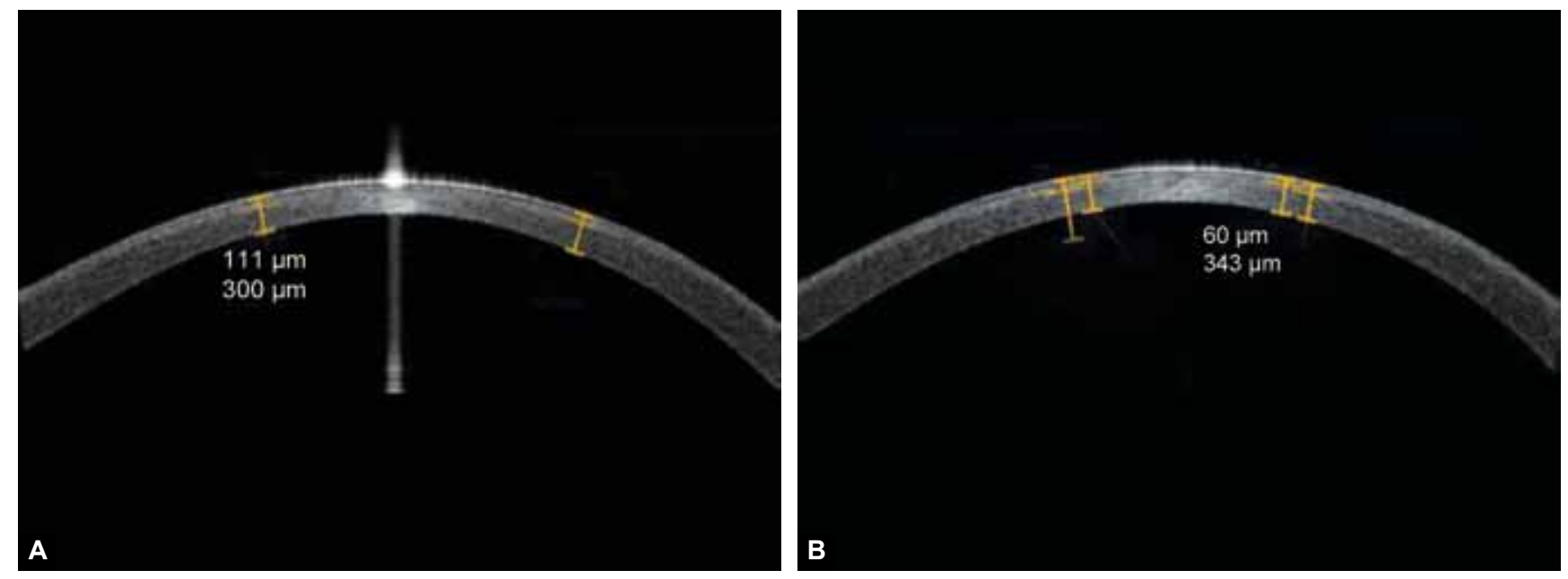

Figs 3A and B: (A) Anterior segment OCT (Visante, Zeiss) of the left (A) and right (B) eye showing a residual stromal bed superior to 300 microns in both eyes

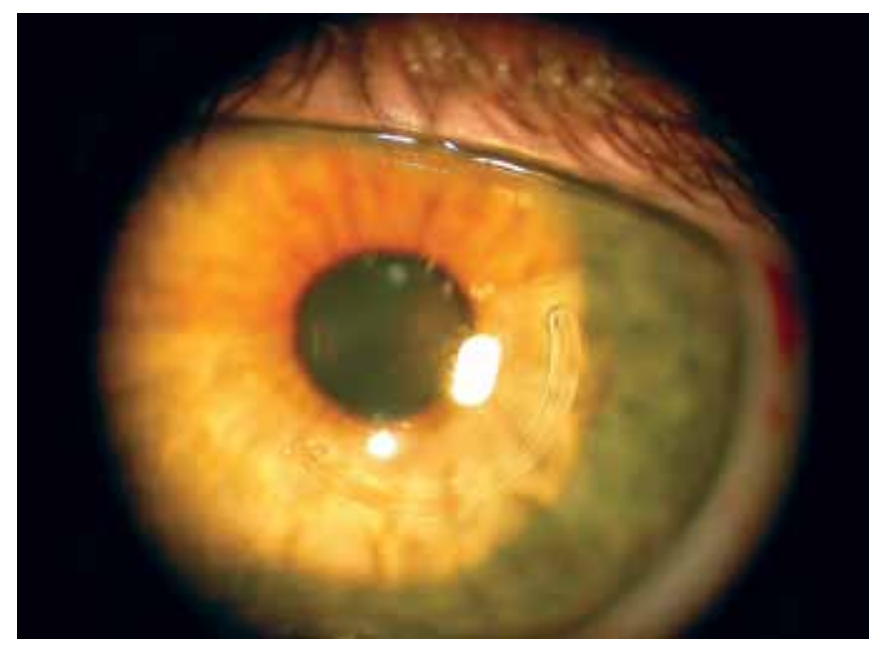

Fig. 4: Well-centered corneal ring

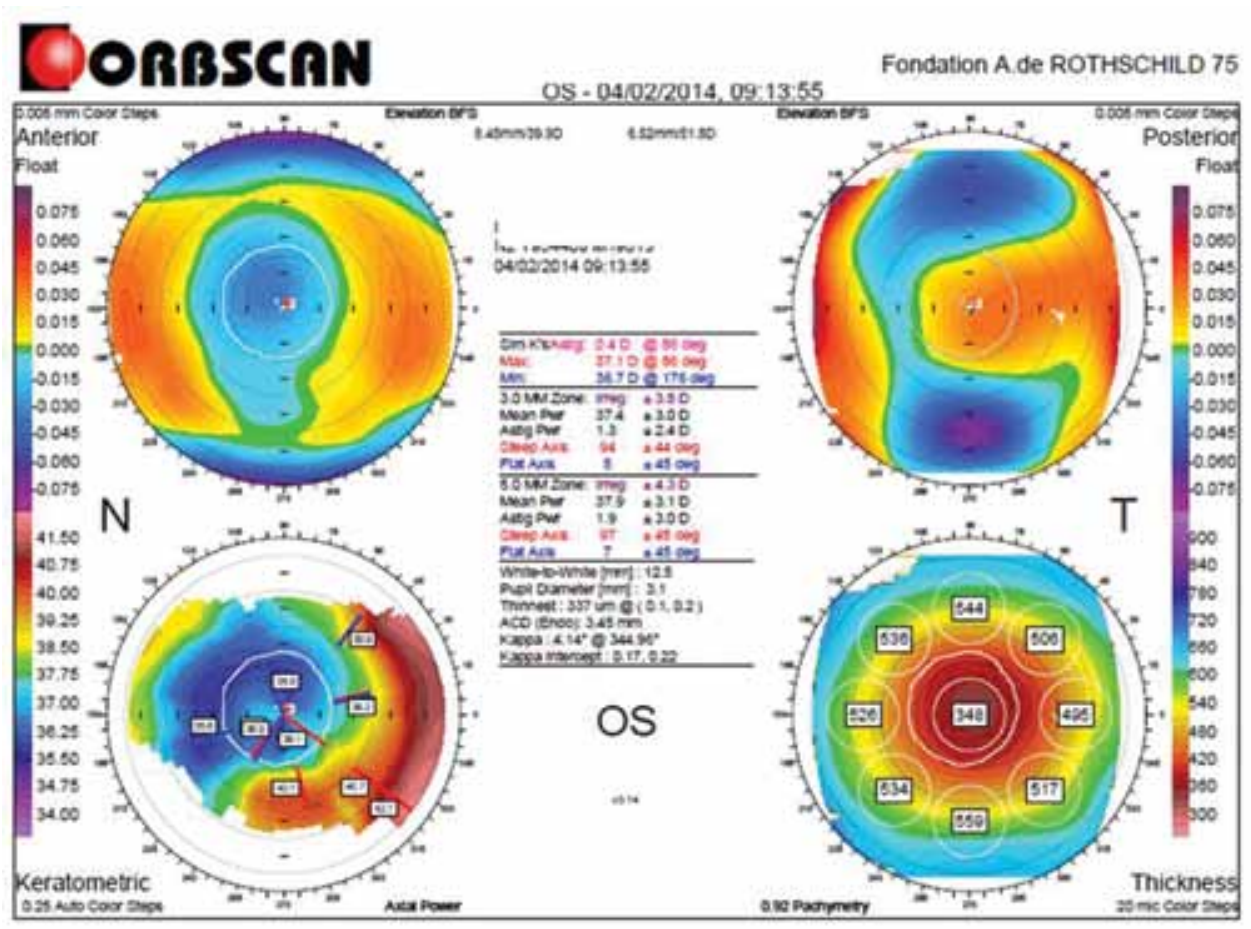

Fig. 5: Left eye topography (Orbscan Quadmap) post ring implantation 
The major established risk factor for ectasia is abnormal preoperative topography suggestive of keratoconus, keratoconus suspect, or pellucid marginal degeneration. In the present case the left eye did not present evident risk factor for ectasia while only the right eye had slight topographical abnormalities. It was previously reported that a difference in central pachymetry between both eyes may represent a risk factor for ectasia. ${ }^{9}$ In this case, slight topographical abnormalities were present in one eye and a post-LASIK ectasia developed in the contralateral eye. Keratoconus is a bilateral disease and both eyes present the same genetic makeup even though one eye may be affected more than the other. It's unclear why in that specific case, ectasia developed in the topographically more normal eye. Laser correction was slightly higher in that eye (correction treated was $-7(-1.50 \times 10)$ in the right eye and $-7(-2.25 \times 170)$ in the left eye with an optical zone of $6.5 \mathrm{~mm}$ in both eyes), but it's difficult to input the development of ectasia to that reason only. Moreover, the stromal bed thickness measured postoperatively showed a RSB higher than 300 microns in both eyes.

Reviews of large numbers of cases report that patient younger than 25 years with a high degree of myopia, a preoperative corneal thickness of $450 \mathrm{~mm}$ or less, and an assumed or calculated residual bed thickness of $240 \mathrm{~mm}$ or less are at higher risk for post-LASIK ectasia. ${ }^{13,22,23}$

The calculated Randleman et $\mathrm{al}^{7}$ ectasia risk score was 2 for right eye and 3 for left eye which suggested that a LASIK procedure was not safe enough regarding ectasia.

Rigid contact lens adaptation is the first line treatment for post-LASIK ectasia. In case of difficult adaptation, intracorneal rings represent an acceptable alternative. The combination of rings implantation and corneal cross-linking has also been proposed, however we decided to consider rings implantation only as there was no evidence of topographical evolution of the ectatic process over a 6 months period.

Improvement in visual acuity and reduction in spherocylindrical error and keratometry have been found after ICRS implantation in post-LASIK ectasia, even in severe cases. ${ }^{24}$ In our case, there was a reduction of corneal astigmatism with a flattening of $2.7 \mathrm{D}$ of $\mathrm{km}$ which is comparable to Alio et al study (3.6D of $\mathrm{km}$ at 6 months postopertively) ${ }^{25}$ or Kymionis et al study ${ }^{26}$ with a mean reduction of $3.07 \pm$ 0.77D (at last follow-up of 10 eyes).

Our observation suggests that a topographic asymmetry between eyes should be considered an additional risk factor for developing post-LASIK ectasia.

\section{REFERENCES}

1. Klein SR, et al. Corneal ectasia after laser in situ keratomileusis in patients without apparent preoperative risk factors. Cornea, 2006;25(4):388-403.
2. Ou RJ, Shaw EL, Glasgow BJ. Keratectasia after laser in situ keratomileusis (LASIK): evaluation of the calculated residual stromal bed thickness. Am J Ophthalmol 2002;134(5):771-773.

3. Pallikaris IG, Kymionis GD, Astyrakakis NI. Corneal ectasia induced by laser in situ keratomileusis. J Cataract Refract Surg 2001;27(11):1796-1802.

4. Parmar D, Claoue C. Keratectasia following excimer laser photorefractive keratectomy. Acta Ophthalmol Scand 2004; 82(1):102-105.

5. Randleman JB, et al. Corneal ectasia after photorefractive keratectomy. J Cataract Refract Surg 2006;32(8):1395-1398.

6. Seiler T, Iatrogenic corneal ectasia after LASIK is the end in sight?. Klin Monbl Augenheilkd 2005;222(5):429.

7. Randleman JB, et al. Risk assessment for ectasia after corneal refractive surgery. Ophthalmology 2008;115(1):37-50.

8. Guilbert E, Saad A, Gatinel D. Unilateral ectasia after LASIK in a patient with abnormal topography but normal tomography. J Refract Surg 2013;29(4):294-296.

9. Saad A, Gatinel D. Bilateral corneal ectasia after laser in situ keratomileusis in patient with isolated difference in central corneal thickness between eyes. J Cataract Refract Surg 2010; 36(6):1033-1035.

10. Saad A, Gatinel D. Retrospective testing of the score for the detection of ectasia susceptibility: a case report of ectasia 7 years after LASIK. Int J Kerat Ect Cor Dis 2013;2(2):73-78.

11. Barbara R, et al. Late onset post-LASIK ectasia. Int J Kerat Ect Cor Dis 2012;1(3):190-195.

12. Binder PS. Analysis of ectasia after laser in situ keratomileusis: risk factors. J Cataract Refract Surg 2007;33(9):1530-1538.

13. Binder PS. Risk factors for ectasia after LASIK. J Cataract Refract Surg 2008;34(12):2010-2011.

14. Schanzlin DJ, et al. The intrastromal corneal ring segments. Phase II results for the correction of myopia. Ophthalmology, 1997;104(7):1067-1078.

15. Nose W, et al. Intrastromal corneal ring: 12-month sighted myopic eyes. J Refract Surg 1996;12(1):20-28.

16. Fleming JF, Wan WL, Schanzlin DJ. The theory of corneal curvature change with the Intrastromal Corneal Ring CLAO J 1989;15(2):146-150.

17. Asbell PA, et al. Adjustability of refractive effect for corneal ring segments. J Refract Surg 1999;15(6):627-631.

18. Salgado-Borges JM, et al. Refractive, tomgraphic and biomechanical outcomes after implantation of Ferrara ICRS in Keratoconus patients. Int J Kerat Ect Cor Dis 2012;1(1):16-21.

19. Ambrosio R Jr, et al. Corneal ectasia after LASIK despite low preoperative risk: tomographic and biomechanical findings in the unoperated, stable, fellow eye. J Refract Surg 2010;26(11): 906-911.

20. Schweitzer C, et al. Screening of forme fruste keratoconus with the ocular response analyzer. Invest Ophthalmol Vis Sci 2010; 51(5):2403-2410.

21. Saad A, et al. Biomechanical properties of keratoconus suspect eyes. Invest Ophthalmol Vis Sci 2010;51(6):2912-2916.

22. Linebarger EJ, et al. Intacs: the intrastromal corneal ring. Int Ophthalmol Clin 2000;40(3):199-208.

23. Tabbara KF, Kotb AA. Risk factors for corneal ectasia after LASIK. Ophthalmology 2006;113(9):1618-1622.

24. Siganos CS, et al. Management of corneal ectasia after laser in situ keratomileusis with INTACS. J Refract Surg 2002;18(1): 43-46.

25. Alio J, et al. Intracorneal rings to correct corneal ectasia after laser in situ keratomileusis. J Cataract Refract Surg 2002;28(9): 1568-1574.

26. Kymionis GD, et al. Management of post-LASIK corneal ectasia with Intacs inserts: one-year results. Arch Ophthalmol 2003; 121(3):322-326. 